\title{
Use of simple collection kits for surface water and precipitation to identify engineered and natural nanoparticles quickly and simply using an ICP-TOF-MS to better inform risk assessments for impact to human health.
}

\author{
AGIL AZIMZADA ${ }^{1,2}$, MADJID HADIOUI ${ }^{1}$, KEVIN J $^{3}$ \\ WILKINSON $^{1}$, PHIL SHAW ${ }^{3}$ AND LUKAS SCHLATT ${ }^{3}$ \\ ${ }^{1}$ University of Montreal \\ ${ }^{2}$ McGill University \\ ${ }^{3} \mathrm{Nu}$ Instruments \\ Presenting Author: Phil.Shaw@ametek.com
}

Nanoparticle (NP) emissions to the environment are increasing as a result of anthropogenic activities, prompting concerns for the ecosystem and human health. In order to evaluate the risk of NPs, it is necessary to know their concentrations in various environmental compartments, on regional and global scales; however, this has remained elusive due to the analytical difficulties of measuring NPs in complex natural matrices. Here, we measure NP concentrations and sizes for Ti-, Ce- and Agcontaining NPs in numerous global surface water and precipitation samples, and we provide insight into their compositions and origins (natural or anthropogenic).

The results link NP occurrences and distributions to particle type, origin and sampling location. NP concentrations were often found to be below $10^{6} \mathrm{NP} \mathrm{mL}^{-1}$ (i.e. $<1 \mathrm{ng} \mathrm{L}^{-1}$ for Ag-NPs; $<100$ $n g \mathrm{~L}^{-1}$ for Ce-NPs; $<10 \mu \mathrm{g} \mathrm{L}^{-1}$ for Ti-NPs), which are levels that do not appear to exceed documented toxicity thresholds for the environment or human health; however, anthropogenic NPs appear to be already predominant in certain areas, such as urban centers. This work lays the foundation for broader experimental NP surveys, which will be critical for reliable NP risk assessments and the regulation of nano-enabled products.

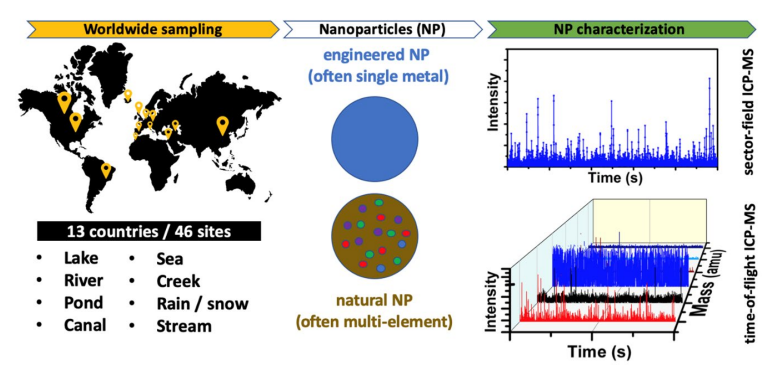

